\title{
El Facundo: un Héroe como su Mito
}

La grandeza de Facundo o Civilización y Barbarie, que Domingo Faustino Sarmiento escribió en Chile, aun cuando al principio se motejara de un gran folletín, es en lo más hondo y vivo de su drama biográfico, de orden arquetípico, de encanto mítico. El mismo Sarmiento, asombrado por la suerte vivificante que había tomado su libro, escribió en la Carta-Prólogo inserta en la segunda edición, en 1851:

Tal como era, mi pobre librejo ha tenido la fortuna de hallar lectores apasionados en aquella tierra cerrada a la verdad y a la discusión, y de mano en mano, deslizándose furtivamente, guardando algún secreto escondido, para hacer alto en las peregrinaciones, emprender largos viajes, y ejemplares por centenas llegar, ajados y despachurrados de puro leídos, a las oficinas del pobre tirano, a los campamentos del soldado y a la cabaña del gaucho, hasta hacerse del mismo, en las hablillas populares, un mito como su héroe. (VII, 16) 1

Serìa casi imposible no admitir la obra dentro de cierto rito instintivo, del espectro que la guia, de ese veni creator spiritu o "secreto escondido", que parte de la letra al espíritu. Sarmiento se vale de la historia para remontarse al misterio, al crimen primordial de una sociedad. Del rito que deriva de la naturaleza, se agrega el mito del hombre, que el artista transforma en el estro de un conflicto, sin solución evidente, pero como una escondida promesa de elevación cívica. Su mito es Quiroga, un hombre que se desploma y muere. Pero su grandeza queda como un sordo trueno, la voz y la sombra para los que todavía seguían vivos. 
Las anécdotas de Quiroga andaban de tapera en galpón, en los rumores populares y en la glosa del romance. Pero Sarmiento termina por darle forma orgánica a ese mito. Y como éste es esencialmente emocional, un drama de las jornadas humanas, atrae más que lo próximo y tiene más efecto hegemónico que la lícita historia. El mito es un orden que se renueva siempre. El primer día del hombre es el de todos los hombres y su destino, la condición de algunos. El mito penetra en el sentimiento popular, en la religión, en la psicología, en las crisis sociales, en la redención colectiva cuya afirmación suele ser válida por lo que niega. El mito es la paradoja de la bondad en la cruz, la gloria en la derrota, la salvación en la muerte, la fuerza en la duda, la verdad en el error. Sarmiento escribió el Facundo para denunciar a un demonio, pero romántico como era, le salió un héroe. Puso en su libro todo su estilo, vigoroso y brillante. "Forzado por el calor febril, como una planta excesiva, aquel libro resultó una creación extraña, que participa de la historia, de la novela, de la política, del poema y del sermón. ${ }^{2}$ En efecto, el Facundo no tiene limitación originaria. Tampoco el estilo puede justificar su destino final. Ni el género ni el estilo pueden explicar la magnitud de Edipo rey, el Libro de Job, la Divina Comedia, el Quijote, Don Juan, Fausto o Moby Dick. Cierto es que el latìn de Virgilio no está escrito en esperanto. Pero existe sin duda un humus entrañable, cuya germinación palpita en el fondo de la palabra y en la de Sarmiento, tan suya, imposible sin el concurso de elementos simbólicos y tensiones míticas. Sarmiento aventuró esta posibilidad en su Carta-Prólogo. Como el resultado, el Facundo escapa a la polémica de los historiadores, cuya misión no es por cierto ver bajo la levisima capa de la teoría política, el fuego encendido. El escritor lo entendió asì: "No vaya el escapelo del historiador que busca la verdad gráfica, a herir las carnes de Facundo que está vivo; no lo toquéis! "(XLVI, 322-23). Este orden subyacente, que es el Facundo mitopéyico, tiene sus propias leyes y su propia realidad operativa apoyada por el acto verbal. 3 Así, toda polémica histórica es vana o minúscula cuando la ficción sobrepasa los argumentos ilustres de la razón. El Facundo mentira, escribió Sarmiento en una carta, siempre será mejor que el Facundo verdadero. $4 \mathrm{El}$ mismo autor se negó siempre a retocar sus páginas, temeroso de que "desapareciera su fisonomia primitiva, y la lozana y voluntariosa audacia de la mal disciplinada concepción" (VII, 16). Tal vez pudiera recordarse aquî el apotegma de que las baladas de un pueblo son más preciosas que sus leyes, por la función noble y genuina que aquéllas tienen en la criatura humana. Sarmiento 
dejó existir el Facundo, asǐ como estaba, más allá de las correcciones de Valentǐn Alsina y de otros cerebros implacables. Como Alberdi, que cuestionó su teoría, Orgaz advirtió que su desarrollo bien pudiera hallarse en Víctor Cousin, y más atrás en Hegel. 5 Sin embargo, la teoría "civilización y barbarie" es parte del acto pretérito de Echeverría, que la anticipó no sin horror en la disyuntiva o encrucijada de La cautiva. Es verosimil que tales errores o fuentes pueden ser enunciadas más de una vez. Provengan, como se ha dicho también, de Montesquieu, de Herder o de Vico, tal paternalismo poco agrega cuando el estro poético alcanza una virtud más irresistible que su influencia. Las circunstancias políticas decaen o mueren, pero el acto de verdadera creación siempre termina por ser vivo y universal. Importa, pues, mucho más hondamente cómo el autor dispone a sus héroes y los presenta como actantes de una sociedad particularmente entendida. Sarmiento hace de los opuestos, como Caĭn y Abel del mito, como Rosas y Quiroga, principios de una ordalía primitiva. Culpables o inocentes, como arquetipos inherentes o probados, la historia asume en el libro los rasgos de sociedades secretas que se auscultan, siempre según un sistema binario y abyecto en pugna por el poder. Pero, invariablemente, el porvenir de las multitudes argentinas estaba en juego. Quiroga fue una de estas víctimas, el infractor de una causa que rudamente quiso llevar más lejos, y por eso fue eliminado. Esta vez triunfó la Esfinge sobre Edipo. Rosas, la traición, la tarea silenciosa y astuta que ambicionaba el poder entero. Su inverosỉmil y aun su increíble presencia, mucho más perfecta que Facundo, era el verdadero enigma, el monstruo. Rosas era, en efecto, el que siempre sacaba partido del acrecido prestigio de las víctimas, llámense Dorrego o Quiroga. Pero un dỉa vendrá, al fin, en que todo se resuelva y el "esfinge Argentino, mitad mujer por lo cobarde; mitad tigre por lo sanguinario, morirá a sus plantas, dando a la Tebas del Plata el rango elevado que le toca entre las naciones del Nuevo Mundo" (VII, 8).

Sin esos raptos visionarios, sin la invención de tales fantasmas, fundados en las inquietudes de una memoria psíquica, la teoría que late en el fondo no sería más que una tesis copiada sin alma, desvaïda y hasta errónea. Podemos incluso deplorar las teorías en un libro que, desde cierta altura crítica y conforme a Mircea Eliade, debiera colocarse en el espirritu del tiempo sagrado. "La fe mitológica -escribió Rojas Paz- es la materia de que están hechas las cosas que pasaron. En la religión los dioses andan por el cielo; en la mitologĩa ambulan por la tierra. 6 
Un libro tan cercano al mito, puede desinteresar al historiador, total o parcialmente, pero no aquello que es claro y natural para el arte, como el Facundo lo es. Esta es una de las mejores pruebas. Nadie lo ha citado como un documento histórico. Es aquí, en efecto, donde la literatura crítica tiene el derecho de apropiarse del mundo de la ficción. Ni cabe que sea de otro modo. De la misma manera, no es la sumisión a un género literario lo que importa, puesto que una obra puede nacer con anticipación a la forma. Cuando Sarmiento escribe, recordemos, el romanticismo traía una revolución frente a los géneros tradicionales. Consta también que el Martín Fierro logra una elocuente victoria sobre los géneros. De ahî su vigor. Sarmiento y Hernández, aun cuando hayan sido rivales en cuanto a los conceptos de civilización y barbarie, no se equivocaron con respecto del arte.

\section{EVOCACION DEL MITO}

Curiosamente, Sarmiento no comienza por narrar la suma de antecedentes históricos. Comienza por el mito, por el carácter funesto del espiritu, donde cree descubrir el misterio contradictorio de la conducta humana. Quien alguna vez se ha interesado por el examen mitopéyico (del griego mithos, fábula y poiein, hacer, crear), sabe que el hombre consiente la leyenda como una respuesta a sus deseos humanos. Sabe que el proceso de una vida humana puede contener todas las inquietudes de la vida universal. Sobre este problema, de matriz ciertamente folklórica, se ha teorizado desde Propp a LéviStraus, de Frazer a Slochower, entre otros. Naturalmente, en el mundo de las creaciones humanas, el héroe tribal o el personaje mítico, crean una serie de oposiciones y relaciones, cuyo mecanismo puede ser simplificado por el análisis estructural. Conforme a este sentido, nadie desconoce que Sarmiento asume en la Introducción, como el punto inicial de una madeja, todo un problema visionario: solicita de Facundo, el caudillo muerto -que vive en la imaginación popular - la clave misma de su experiencia, como árbitro decisivo frente al complejo destino:

¡Sombra terrible de Facundo! voy a evocarte, para que, sacudiendo el ensangrentado polvo que cubre tus cenizas, te levantes a explicarnos la vida secreta y las convulsiones internas que desgarran las entrañas de un noble pueblo. (VII, 7)

Facundo, condenado para siempre, resume el alma, el carácter insensato cuyo coronamiento es la barbarie y la muerte. Pero Sarmiento reacciona frente a esta muerte y la dispara contra Rosas, el 
enemigo más odiado. Su acto vocativo es, después de todo, la inversión de una condena y, mucho más, el deseo de despertar a la vida, como en el apocalipsis, a los muertos. La tragedia de Barranca-Yaco resume el sitio real de la pasión de la república, el paso por la noche oscura de la barbarie. De ahï el clamor a las fuentes secretas de la tumba. Quiere además, dejarse guiar por la sombra imperiosa del caudillo derrotado y sacar de alli, de la nebulosa del mito cívico, la verdad:

Tú posees el secreto, ¡revélanoslo! Diez años aún después de tu trágica muerte, el hombre de las ciudades y el gaucho de los llanos argentinos, al tomar diversos senderos en el desierto, decǐan: ¡No! ¡No ha muerto! ¡Vive aún! ¡El vendrá! (VII, 7-8)

Dedúcese asî, de modo natural como ocurre en los mitos, que el héroe es capaz de morir y renacer. Nada más lógico, por tanto, que Sarmiento haya tomado a Facundo como núcleo vital de su libro. El ser que imagina y el real imaginado son mucho más solidarios de lo que pudiera creerse. Sarmiento pregunta y también su respuesta es violenta. Narra con la misma intensidad facúndica del caudillo evocado. Busca, como un supersticioso, en los hechos humanos, valores imaginarios que una escritura de combate exalte y defina. Pero en el fondo, Facundo es un símbolo espectral y como tal, un mito cuyo gesto sólo puede definirse según la energía de la ficción, en su realidad entera, en su folktale. He aquil el movimiento primitivo de una densidad constitutiva, congruentemente literaria. Lo mismo cabria decir de su composición, visiblemente desdoblada, de proyección ulterior. Sarmiento se abandona a ese culto, al demiurgo secular del país que, muerto, se reencarna en otro ser superior: Rosas, mucho más déspota que el tigre llanero. Desplaza, asî, el núcleo imperfecto de la barbarie, al puro arbitrio del poder satánico, a las tinieblas absolutas, paradójicas, de la Santa Federación.

Pero Sarmiento se detiene poco en la persona de Rosas. Cuando habla de él, mucho más en la tercera parte, sólo menciona su sistema, el cobarde espionaje montado o la siniestra Mazorca. Rosas era, en el fondo, un burgués de cuchilla, un gobernador de propiedades, colonial, sin visión de futuro. Quiroga, en cambio, brillaba por sus desigualdades bárbaras, con apego a las riquezas, pero que podía jugar en una noche su fortuna en los naipes, puesto que "respetaba menos la propiedad que la vida" (VII, 211). Ambos eran disimiles en adular o fanatizar. Rosas era, de cabo a fin, una fiera sin estro, frío en el vicio, sin el titanismo romántico de Facundo. Tales presunciones 
serán legitimas después. Murió en Southampton sin haber combatido en Caseros. Pero a Facundo se lo llevó la muerte, en el mismo orden turbulento en el que vivió. Facundo no era el instrumento de la justicia y la libertad, pero Sarmiento parece admirarlo eventualmente. Puede decirse asi que, detrás de la facundofobia, el mismo personaje produce una imagen muy distinta, tal vez, del proyecto vislumbrado. Si se recuerda, la biografía de Facundo se remonta inicialmente a la famosa escena de la travesía del caudillo perseguido en el desierto por un tigre. Se expresa asì el hecho en el que el héroe, al ultimar el tigre cebado, se transfigura de algún modo en su naturaleza animal y adquiere su fuerza sanguinaria. "Algunas veces -escribe Gubernatis- los héroes o los dioses toman la forma de un félido para vencer a sus enemigos, como Dionisios, Apolo o Heracles en Grecia e Indra y Vishnú en la India."7 Tal es, pudiera decirse, conforme a un sentimiento totémico, como abunda en la mitología o en el cuento maravilloso, el hombre-animal que el inconsciente primitivo traslada a las fantasias populares. Verdadero virtuoso en el manejo de tales especies míticas, Sarmiento enfatiza estas llamativas correspondencias. Cuando fisonomiza la forma bestial del caudillo, o sus ojos, su mirada es semejante a la del tigre. No es un detalle más. Esa mirada es tan importante que se siente tentado continuamente a mencionarla y será, atando cabos, significativa del drama final:

Sus ojos negros, llenos de fuego y sombreados por pobladas cejas, causaban una sensación involuntaria de terror en aquellos en quienes alguna vez llegaba a fijarse, porque Facundo no miraba nunca de frente, y por hábito, por arte, por deseo de hacerse siempre temible, tenia de ordinario la cabeza siempre inclinada, y miraba por entre las cejas, como el Alí-Bajá de Montvoisin. (VII, 72)

Sarmiento recurre, más de una vez, a los más patentados hechos de la leyenda. Su polifonía mitológica raya en lo febril. Como Sansón, por ejemplo, le concede a Facundo una fuerza extraordinaria capaz con el macho de los grillos de sembrar una ancha calle de cadáveres. (VII, 77) Pero, curiosamente, como el personaje bíblico, será engañado y vǐctima de la traición. Adviértase cómo se vale de otras formas sucedáneas:

$\mathrm{Su}$ cólera era la de las fieras; la melena de sus renegridos y ensortijados cabellos caían sobre su frente y sus ojos en guedejas, como las serpientes de la cabeza de Medusa; su voz se enronquecía; sus miradas se convertían en puñaladas. (VII, 79) 
Sin duda, podrían tomarse tales especies mitológicas como signos expresivos, sin mayor incidencia en lo que el autor se propone decir. Sin embargo, la caracterización del personaje, como se verá después, forma parte de un sistema complejo que sigue los pasos perfectamente precisos del relato mítico. Si los ojos de Facundo fulminan, como puede entenderse por la mención de Medusa o pueden atemorizar al ladrón de una montura que tiene que confesar su culpa, no difiere él asimismo de su condición de ogro o duende terrible al ser reconocido por un grupo de niños desprevenidos:

Facundo se presenta un día en una casa, y pregunta por la señora a un grupo de chiquillos que juegan a las nueces; el más atisbado contesta que no está. -Dile que yo he estado aquil. - ¿Y quién es usted? -Soy Facundo Quiroga. El niño cae redondo, y sólo el año pasado ha empezado a dar indicios de recobrar un poco la razón; los otros se echan a correr llorando a gritos; uno se sube a un árbol, otro salta unas tapias y se da un terrible golpe. . . (VII, 175)

Indudablemente, no puede interpretarse este episodio en términos históricos. No sabemos si el autor nos propone una burlerìa bien disimulada, o una ficción, cómica y terrible a la vez. Tales hechos mundanos de Quiroga no son, por cierto, políticos. Facundo es, a todas luces, un centro magnético tan misterioso como paradójico. También los taumaturgos de la pampa, el rastreador o el baquiano, eran seres que operaban sobre el nivel de los hombres corrientes. Muchos de los caudillos que menciona Sarmiento gozaban de tales predicamentos. Lo mismo el gaucho malo o el cantor que, como Quiroga o Lamadrid, eran seres que el lector bien puede ubicarlos en su casillero o función escénica. He aquí otra fórmula arquitectónica del Facundo: la de suponer a los personajes en el habitáculo de un prototipo popular, en el que tal vez la realidad coincidió alguna vez.

\section{EL NIÑO REBELDE, EL FORAJIDO}

Como manifestación preliminar de las fuerzas que el mito pone en juego, figura la infancia del héroe, generalmente un rebelde social, hostil con sus padres o dispuesto a romper un tabú establecido. Muy a propósito, se lee:

Cuando un hombre llega a ocupar las cien trompetas de la fama con el ruido de sus hechos, la curiosidad o el espiritu de investigación, van hasta rastrear la insignificante vida del niño, para anudarla a la biografía del héroe; y no pocas 
veces entre fábulas inventadas por la adulación, se encuentran ya en germen en ella los rasgos característicos del personaje histórico. (VII, 72)

Histórico, dirǐamos, al modo como Moisés, Ciro, Rómulo, Jesús o Sigfrido, cuyos actos simbólicos, devueltos por la leyenda o la literatura, revelan la majestad humana del mito. Sarmiento llega a comparar la infancia de Facundo a las cualidades naturales de Alcibiades o Napoleón, no para vindicarlo, sino con el propósito de exaltar su grandeza inútil. Sin embargo, nada de la vida ya realmente genuina de Napoleón o Alcibiades debió iniciarse con un crimen como el caso de Orestes, Edipo, Rómulo o el Cid de las mocedades. Y Facundo llega aqui, tempranamente, a eso. En efecto, Facundo comienza por dar, a la edad de once años, una bofetada a un maestro. Va a esconderse después en ciertos parrones de una viña, de donde no se le saca en tres días. Nadie puede sentarlo a la mesa donde, por casualidad, se hospeda, y al fin, cuando llega a la pubertad, por un balazo dado a un tal Jorge Peña, "derrama el primer reguero de sangre que debía entrar en el ancho torrente que ha dejado marcado su pasaje en la tierra" (VII, 73).

Según el mito, el crimen del héroe constituye la primera caída dentro de las jornadas de su tiniebla. Es el momento que nada deplora, porque se inicia en el ejercicio de su propia fuerza. Facundo se convierte en gaucho errante, domina sobre sus enemigos personales y conoce su poder, que amansa voluntades, en el empleo de su coraje sin fatiga. Después, en plena juventud, "el hilo de su vida se pierde en un intrincado laberinto de vueltas y revueltas por los diversos pueblos vecinos; oculto unas veces, perseguido siempre, jugando, trabajando en clase de peón, dominando a todos los que se le acercan y distribuyendo puñaladas" (VII, 73). Tal es el hombre, el titánico Facundo que mata al juez Toledo porque le exige sus documentos de conchavo, desertor, además, del Ejército de los Andes y quien, asombrosamente, incendia la casa paterna. Como Satanás, no parece contar con la gracia divina, pero el contrasentido de la Providencia le hace decir a Sarmiento que ésta "realiza grandes cosas por medios insignificantes e inapercibibles, y la unidad bárbara de la República va a iniciarse a causa de que un gaucho malo ha andado de provincia en provincia levantando tapias y dando puñaladas" (VII, 111). Pero Facundo no es el venturoso arquetipo del medio y las circunstancias. Para Sarmiento, Facundo aprendió tarde el poder que educa. Este hombre, que habiase iniciado con todas las formas de la violencia, llevará en sí su propia muerte, a la que quiso burlar, como en el 
poema de Borges, muy orondo. Sin embargo, su destino, tal como pensaba Sarmiento, contribuiría a la evolución de la historia, para hacer de la vida la muerte, una sombra que ofende el espirritu nacional, pero a quien el autor -como Eneas o Hamlet, a la sombra de su padre - le pide una respuesta. Facundo queda vivo, según Sarmiento, porque el pueblo le había concedido la gracia última del mito, es decir, su misterioso regreso de "sombra".

\section{EL MISTERIO DEL MANDO}

Sarmiento, que prefirió el Facundo de la leyenda y no el de la historia, elaboró, quizá sin saberlo él, aspectos tanto causales como finales del relato mítico. No era por cierto el suyo el hombre normal, cuya apología hicieron después David Peña o Pedro de Paoli. No era tampoco el héroe tradicional o romántico que arranca del adversario a la mujer que ama. Facundo no estaba destinado a amar. Como no posee el sentido erótico de la realidad, sus actos de pasión son meras acciones truculentas. Ninguna mujer se presta a su amor. Severa Villafañe, santificada por el autor, termina escondiendo su virtud en un beaterio, que el Tigre de la Rioja no logra violar. Asimismo ocurre con la dama tucumana que no accede a sus requiebros, puesto que la vigilancia del padre, termina por cerrar las puertas de su casa al rudo galán de tantas empresas militares. Curiosamente, en estos casos, Facundo termina vencido por pobres recursos. La meta de su destino nunca llega al amor, al amor pasión asî entendido, que el autor destaca como una forma más de su capricho inútil. En cambio, los actos de Facundo son más bien jornadas o procesos de una realidad social mucho más amplia. Cuando Sarmiento lo compara a Tarmelán o Mahoma, es porque el mando del jefe o caudillo resume en el ámbito de la pampa su más alta profesión. Cuenta, en estos casos, la sucesión paulatina del poder. Y como el autor no separa al caudillo del sistema, es natural que su ascenso se consiga a través de sucesivas etapas, especie de cosmogonía gnóstica, por las que debe pasar el montonero de prestigio: esto es, de la rebeldía natural al dominio múltiple del caballo y del temible cuchillo; del círculo olímpico de la pulperia -que prueba la fama del cantor o del jinete - al juez de paz, y de allí a comandante de campaña; un salto más, podrá contar con hombres que le siguen y habrá alcanzado la cima mítica del caudillo.

Y Facundo fue uno de los mejores en llegar, por propensión clandestina y sin embargo popular, a tal ejercicio del poder. Era lógico que, como el barón feudal, invocara la Providencia, para mandar a degollar en masa. "Pasaba por las ciudades -recuerda' Martínez Estrada - como el ángel vengador y esa tenacidad en lo 
bárbaro podía convencer al fin que estaba en lo cierto."8 Adecuado resulta, por ejemplo, este caso, testimonio que nadie ha desmentido de la vida de Facundo:

Sofocada la revolución de San Juan, sábese un dỉa que Facundo está a las puertas de la ciudad con una bandera negra dividida por una cruz sanguinolenta, rodeada por este lema: ¡Religión o Muerte! (VII, 120)

He aquí el viejo lema español con vigor extraordinario en su nuevo transplante. Y es que Facundo, a estas alturas del poder, se llama El enviado de Dios, no obstante que "nunca se confesaba, ni oỉa misa, ni rezaba, y él mismo decỉa que no creỉa en nada" (VII, 120). Su misión divina era, por entonces, la guerra. Facundo se sentía profeta. Vicente Fidel López recuerda que Facundo "leyendo la Biblia se había figurado que él también había nacido para ser el fuego purificador de las iras de Jehová."9

La postura de Facundo es, en este estadio del relato, de "redentor de los pueblos". Corre el año de 1826. Como no ha caído la república representa la tercera fuerza que se abre paso entre federales e unitarios, "aquello que se estaba removiendo y agitando desde Artigas hasta Facundo, tercer elemento social, lleno de vigor y de fuerza" (VII, 131). Es pues, nada más que el instinto de la campaña pastora frente a los hombres de la ciudad, Dorrego y Rivadavia. El hecho de que Facundo viniera tragando territorios y provincias, con un desafuero de apocalipsis, convencido de su capacidad y poder, en su vida late el deseo de destruir para transformar:

Se sentía fuerte y con voluntad de obrar; impulsábalo a ello un instinto ciego, indefinido, y obedecǐa a él; era el comandante de campaña, el gaucho malo, enemigo de la justicia civil, del orden civil, del hombre decente; del sabio, del frac, de la ciudad, en una palabra. La destrucción de todo esto le estaba encomendada de lo Alto, y no podia abandonar su misión. (VII, 120)

Sarmiento coloca a Facundo en su rebelión esencial, porque era dialéctico suponía que a pesar del presente bárbaro, el país entraría en vìas de transformación definitiva. $\mathrm{El}$ fondo de su creencia era ésta: "Facundo era el tipo más ingenuo del carácter de la guerra civil" (VII, 14) Intuyó, conforme a pautas dramáticas, que debia elevarlo a un absurdo desmedido e ignorante, para verlo caer, y cuando, habiendo corregido éste sus defectos más sectarios, se plantara por fin con nueva arrogancia frente a Rosas. 
Por esto Sarmiento no acude siempre a lo siniestro. Le pareció que el "buen humor" de Quiroga no debía "ser ignorado" (VII, 92). He aquí cómo el gaucho hereje, no obstante sus propensiones míticas, se entrega a sus caprichos:

Estas escenas con los sacerdotes son frecuentes en el Enviado de Dios. En San Juan hace pasearse a un negro vestido de clérigo, en Córdoba a nadie desea coger sino al doctor Castro Barros, con quien tiene que arreglar una cuenta; en Mendoza anda con un clérigo prisionero con sentencia de muerte, y es sentado para ser fusilado; en Atiles hace lo mismo con el cura de Alguia, en Tucumán con el prior del convento. Es verdad que a ninguno fusila; eso estaba reservado a Rosas. . . (VII, 120)

Sarmiento se lamenta, incluso, de haber omitido muchas anécdotas de Quiroga. Le pareció también que las graciosas o sutiles eran certeras. Porque para el autor no se trataba de recurrir a la perversidad de Facundo, sino mostrar la diferencia con Rosas, que no poseía más humor que el expresado por sus bufones. Pero Facundo era franco e incluso de altiva capacidad de renunciación. Podía cambiar $\mathrm{y}$, de súbito, tender una mano al mismo enemigo. Así como en su juventud vuelve a la casa paterna y échase a los pies del anciano ultrajado (VII, 77), curiosamente, mientras pone en Tucumán un presidente, el doctor Ortiz -que se irá con él a la muerte en BarrancaYaco -, le preocupa, como un niño sin su juguete, que Estanislao López tenga todavǐa en su "poder su caballo moro, sin mandárselo" (VII, 181) Tal es la modalidad de su psique, entre cuyos dramas figura también el de sus ritos. Lugones también nos dice que "aquel moro de Quiroga, recuerda al Xanthos de Aquiles: habla y augura. Su amo, después de la Tablada, hace como los paladines del siglo XI: no se cortará la barba hasta haberse vengado."10 En efecto, esa batalla, de la que salió victorioso el general Paz, fue su afrenta de Corpes. De otros también quería vengarse; de Lamadrid que desenterró sus tapados (VII, 182) Y Quiroga no tiene más que culpar de estos fracasos a la ausencia de su moro brujo. Mientras tanto Rosas, que vuelve "héroe" del desierto, se encumbra en Buenos Aires. La vida de Quiroga parece entrar, por fin, en el último laberinto. De carácter errante, no le gusta nunca pertrecharse en un solo lugar. Siempre que toma una provincia, delega en otros su gobierno. Era demasiado impaciente para ser un jefe de partido de cabildeo y burocracia. Tenía sed de gloria antes que ambición, por eso ahora, frente a Rosas, no guarda resentimientos contra los unitarios. "El único argentino que 
se interesa por Rivadavia -escribe Lugones que comenta el librocuando va a abandonar el país, desterrado y pobre, es Facundo Quiroga, que ofrece su fianza para salvarlo del ostracismo, y arriesga por despedirlo un chapuzón en el río."11 Tal era el Facundo de la historia, pero también el Facundo virtual de Sarmiento.

\section{VIAJE A LA SOMBRA}

Cuando Facundo comienza a abandonar la instintividad propia de la pampa y se arrepiente de haber rechazado la constitución de 1826, dos cosas ocurren: Quiroga camina a su fin, y en el bando opuesto, Lamadrid y Lavalle están prácticamente derrotados. El Tígre de los Llanos, que invocaba sólo la guerra como fuego del cielo, finalmente se le ocurre que el paǐs debe ser reivindicado por la garantỉa de la ley y la paz. Va, pues, a sentar cátedra en la misma sede del tirano:

Facundo se establece en Buenos Aires, y bien pronto se ve rodeado de los hombres más notables; compra seiscientos mil pesos de fondos públicos; juega a la alta y baja; habla con desprecio de Rosas; declárase unitario, y la palabra Constitución no abandona sus labios. (VII, 187)

Pero Rosas, menos ingenuo que Quiroga, calla, en tanto piensa que la dictadura es más eficaz que la ley. La fulgorosa fantasía de Facundo se vuelve peligrosa en su redil y, además, herética para su clase y la Mazorca. Es entonces cuando Juan Manuel inventa la singular misión de restaurar el entredicho de los gobernadores de Salta y Tucumán. El epilogo mitopéyico está dado por la gradual y última aventura de Facundo que, picado en su orgullo y en un rapto de misticismo político, decide viajar al Norte en galera y sin escolta. Pero el tigre se equivoca al invertir un orden práctico que él nunca hubiera aconsejado. Facundo ha dado demasiado crédito a su propio mito al no calcular que la naturaleza del destino estaba por encima de él y del espíritu cívico de Rivadavia, a quien parece imitar.

Juan Alfonso Carrizo indica que el capítulo IX, el más dramático de todos, fue casi una copia de un cantar popular hallado primero en un viejo cuaderno salteño y luego en la tradición oral de La Rioja. 12 Aun cuando los pormenores del viaje y la muerte de Quiroga se los facilitara "el malogrado doctor Piñero", como asegura Sarmiento en la edición de 1851, nada invalida la tesis de Carrizo. La base estructural del relato es la misma, aunque naturalmente, según su prosa. Pero Sarmiento elimina la interpolación irónica de un loro, por ejemplo, para agregar en cambio el trayecto del chasque que 
aventaja a la galera, cuyo propósito era anunciar a los Reinafé el día fijo y la hora en que pasaría por las postas. Nadie ignora que el chasque ha salido de Buenos Aires e inquieta gradualmente a Quiroga. De este modo el espiritu del episodio se subordina a la sentencia de muerte que el invisible Rosas ha decretado, cuyo instinto maquiavélico sabe manejar entre bambalinas los títeres de la tragedia final. Quiroga será el viajero que parte vertiginosamente hacia el destino que le espera, cuyo propósito último se ignora, puesto que al morir se llevó con él secretos nunca revelados. Creyóse Mesías ya tarde, pero a diferencia del bíblico, tuvo que cargar con el pecado bárbaro de un falso terror sagrado y fue a morir porque quiso alcanzar una gloria sospechosa. Quizá Sarmiento no intentó tal penetración mitopéyica, pero su instinto fue infalible. El Facundo no es una simple reunión de datos, de crueles y amargas verdades de libelo. $\mathrm{Su}$ arrebato lírico es enteramente cíclico, tan justo en su fondo mítico que se va desarrollando con el inusitado vigor del dilema y la paradoja. Porque es sabido que Facundo viajó en una galera roja, curioso objeto y obsequio del Restaurador. Pero contra todos los anuncios, contra los temores que quieren detenerlo, Facundo ofrece un desafío y una provocación temeraria. Teme instintivamente, sin embargo, puesto que antes de partir saluda a Buenos Aires: "Si salgo bien, dice, agitando la mano, te volveré a ver; si no jadiós para siempre!" (VII, 192).

Con toda propiedad, pues, puede decirse que la creación de Sarmiento es enteramente dramática. Sabe darle color al paisaje y a Facundo entre las circunstancias. Acentúa, en efecto, la paradoja de su propósito de contrariar a Rosas, la magnitud del espacio y del tiempo que dificultan su misión, la falta de caballos, la lluvia torrencial, las pesadillas del doctor Ortiz, su acompañante; la reputación de Santos Pérez, la gente que le anuncia, cruzándose con él en el camino, el lugar preciso de la emboscada. Pero Facundo no se detiene, ni cambia de camino como se le aconseja. Sarmiento se pregunta:

¿Qué genio vengativo cierra su corazón y sus oỉdos, y le hace obstinarse en volver a desafiar a sus enemigos, sin escolta, sin medios adecuados de defensa? ¿Por qué no toma el camino de Cuyo, desentierra sus inmensos depósitos de armas a su paso por La Rioja y arma a las ocho provincias que están bajo su influencia? (VII, 194)

Tal es el momento crucial en que el héroe debe elegir, la salvación, que lo coloca entre los cobardes, o ganar con su muerte una 
victoria moral. Tal es, también, el clímax o desenlace del que depende la singularidad de la mitopéyica. Facundo, pues, se niega a volver por el camino, rumbo a su tierra, que todos le aconsejan. Nadie sabe, ni Sarmiento explica la razón de tan extraño designio, de volver empeñosamente a Buenos Aires. Sólo David Peña, su historiador y dramaturgo, se atreve a sostener que Facundo regresa para vengarse de la traición. Lo cierto es que tal desafio es la ilusoria y última vanidad del tigre, cuyas visiones le hicieron pensar que podía toparse por fin realmente con el gigante que custodia el tesoro de la federación. Esta lógica no es absurda; es lo que debe ser. O el héroe regresa para transformar la sociedad, o muere. Su gesto es, en el plano mitopéyico, natural. Como Lucifer cegado y precipitado en las tinieblas, no llega a mártir porque su causa estaba perdida. Su error lo consumirá en el fuego, puesto que es significativo que Sarmiento no omita el hecho -que figura en los cantares y romances populares- de que Santos Pérez descargue su pistola en los ojos de Quiroga, de los que hizo todo un símbolo de poder y terror:

Llega al punto fatal, y dos descargas traspasan la galera por ambos lados, pero sin herir a nadie; los soldados se echan sobre los sables desnudos y en un momento inutilizan los caballos, y descuartizan al postillón, correos y asistentes. Quiroga entonces asoma la cabeza, y hace por el momento vacilar a aquella turba. Pregunta por el comandante de la partida, le manda acercarse, y a la pregunta de Quiroga ¿Qué significa esto?, recibe por toda contestación un balazo en un ojo, que le deja muerto. (VII, 196)

El resto corresponde a una tragedia de consecuencias: la del gaucho cordobés Santos Pérez, "hombre de palabra", y la de los hermanos Reinafé, vǐctimas de la obra maestra del nuevo prìncipe de las tinieblas, pero mucho más sinuoso y escondido, cuya boca sin labios, sin ojos que parpadean, alguna vez se ha comparado con una vibora.

El libro de Sarmiento no puede explicarse sin Quiroga y Rosas. Sin embargo, al finalizar la tercera parte, como enlazando una esperanza y el sentido circular del Facundo, Sarmiento invoca esta vez a la Providencia para que condene al asesino e inspire las fuerzas de la civilización:

¡Proteja Dios tus armas, honrado General Paz! ¡Si salvas la República, nunca hubo gloria como la tuya! ¡Si su- 
cumbes, ninguna maldición te seguirá a la tumba! ¡los pueblos se asociarán a tu causa, o deplorarán más tarde su ceguedad o su envilecimiento! (VII, 252)

University of Vermont

ARMANDO ZARATE

\section{NOTAS}

1. Los números entre paréntesis corresponden a las páginas a las Obras Completas de Sarmiento publicadas por Augusto Belin, Paris-Buenos Aires, 1899-1909. p. 119.

2. Leopoldo Lugones, Historia de Sarmiento. Buenos Aires: Babel, 1931,

3. Según Raúl H. Castagnino, "En las modalidades cuentisticas, dichos conceptos tornan tangible el acto creador, el poieo, la estructuración ficcional, los artificios. Como en la epopeya o en la novela, también evidencian la estructura de un universo verbal. No su descripción o explicación; no la simple enumeración o inventario de componentes; no su filosofía, sino un objeto nuevo y diferente, un "artefacto" cuyo mecanismo, válido de los recursos y artificios de una técnica, sostiene una icción, ya proceda ésta de lo mítico o de lo real." Cuento-artefacto y artificios del cuento. Buenos Aires: Editorial Nova, 1977, p. 46.

4. Cf. Paul Verdevoye, Domingo Faustino Sarmiento. Paris: Institut des Hautes Etudes de l'Amérique Latine, p. 412. 306.

5. Raúl A. Orgaz, Sociologia Argentina. Córdoba: Asandri, 1950, t. II, p.

6. Pablo Rojas Paz, Lo pánico y lo cósmico, Buenos Aires: Losada, p. 38. Angelo de Gubernatis, Zoological Mythology. New York: Macmillan, 1872, t. II, p. 158.

8. Ezequiel Martìnez Estrada, Radiografía de la pampa. Buenos Aires: Losada, 1968, n. p. 46.

9. Historia de la República Argentina. Buenos Aires: Editorial La Facultad, 1926, t. X, p. 15.

10. Lugones, op. cit., p. 121.

11. Ibid, p. 82.

12. "Sarmiento y el cantar tradicional a la muerte del General Juan Facundo Quiroga.", en Sustancia. Tucumán: 1930, I, pp. 9-18. 
